\title{
Studies on packaging and storage of red capsicum (cv. BOMBY) at different storage conditions
}

Sheetal Mane and V. P. Kad

Received : 18.01.2019; Revised : 14.02.2019; Accepted : 05.03.2019

See end of the Paper for authors' affiliation

Correspondence to :

Sheetal Mane

Department of Agricultural

Process Engineering,

K.K.Wagh College of Agricultural Engineering and Technology, Nashik (M.S.) India

Email : manesheetal_38@ rediffmail.com
-ABSTRACT : The effect of different packaging materials along with two storage conditions i.e. Zero Energy Cool Chamber (ZECC) and Cold Storage (CS) on quality attributes and shelf-life of red capsicum were investigated. The quality parameters assessed were physiological loss in weight, firmness, rotting, ascorbic acid and moisture content. The red capsicum fruits in all the treatments showed increasing trends of physiological loss in weight $(\%)$, TSS $\left({ }^{\circ} \mathrm{B}\right)$ and rotting $(\%)$ while moisture content, ascorbic acid $(\mathrm{mg} / 100 \mathrm{~g})$ and firmness $(\mathrm{N})$ showed decreasing trend during storage period in ZECC and CS. The quality of capsicum fruits of red varieties under CS and ZECC were found to be best when packed in cellulose acetate (CA) film followed by breathing bags. The shelf-life of red capsicum fruits was extended upto 40 days in CS, 24 days in ZECC when packed in CA film followed by breathing bags. The CA films was found to be best packaging material for extending the shelf life followed by breathing bags and polythene bags of 100 micron, 50 micron and 25 micron, in CS as well as ZECC storage in respect of quality parameters.

- KEY WORDS : Capsicum, Cv. BOMBY (red), Shelf-life, Cold storage, Zero energy cool chamber, Chemical properties

- HOW TO CITE THIS PAPER : Mane, Sheetal and Kad, V.P. (2019). Studies on packaging and storage of red capsicum (cv. BOMBY) at different storage conditions. Internat. J. Agric. Engg., 12(1) : 78-86, DOI: 10.15740/HAS/IJAE/12.1/78-86. Copyright@2019: Hind Agri-Horticultural Society. 